\title{
The effect of homelessness on viral
} suppression in an underserved metropolitan area of middle Tennessee: potential implications for ending the HIV epidemic

\author{
Vladimir Berthaud ${ }^{1 *} \mathbb{B}$, Livette Johnson ${ }^{1}$, Ronda Jennings ${ }^{1}$, Maxine Chandler-Auguste ${ }^{1}$, Abosede Osijo ${ }^{1}$, \\ Marie T. Baldwin', Patricia Matthews-Juarez ${ }^{3}$, Paul Juarez ${ }^{3}$, Derek Wilus ${ }^{2}$ and Mohammad Tabatabai
}

\begin{abstract}
Background: A wealth of scientific evidence supports the effectiveness of HIV prophylaxis and treatment. Homelessness is strongly associated with the health status and viral suppression among underserved populations and can undermine the national plan to eliminate HIV by 2030. This retrospective observational study examined the extent in which homelessness affects HIV treatment in an underserved urban area of Middle Tennessee in 2014-2019.

Results: Among 692 HIV-seropositive patients, the proportion of homeless patients increased from 13.5\% in 2014 to 27.7\% in 2019, thrice the national average for HIV-seropositive people (8.4\%) and twice that of HIV positive patients who are participating in Ryan White programs nationwide (12.9\%). Our findings suggest that homeless patients were half as likely to achieve viral suppression as compared to those who had a permanent/stable home [OR 0.48 (0.320.72), p-value $<0.001]$.
\end{abstract}

Conclusion: Our study indicates that homelessness may play an important role in viral suppression among persons living with HIV/AIDS in Middle Tennessee.

Keywords: Homelessness, HIV, Social determinants, And viral suppression

\section{Background}

HIV has become a chronic condition, easily manageable by taking one multi-drug, single daily pill. However, the HIV epidemic continues to affect predominantly minorities of color, underserved and marginalized populations including persons experiencing homelessness. The Center for Disease Control and Prevention (CDC) estimates that 1.2 million people aged 13 and older were living with HIV in the United States and 37,832 persons were newly diagnosed HIV-seropositive in 2018 [1]. Of

\footnotetext{
*Correspondence: vberthaud@mmc.edu

${ }^{1}$ Division of Infectious Diseases, Meharry Community Wellness Center,

Meharry Medical College, Nashville, TN, USA

Full list of author information is available at the end of the article
}

them, Black/African American represented 42\%, while they account for just $13 \%$ of the U.S. population. Overall, the number of new infections remains unacceptably high, especially among men having sex with men (MSM) in the age group $25-34$, while there has been a $42 \%$ increase in the incidence rate between the Black/African American and Hispanic/Latinx racial groups.

\section{Homelessness and HIV-related health outcomes}

HIV-seropositive persons are disproportionately overrepresented among the homeless population. In 2016, the CDC reported that $8.4 \%$ of people in HIV medical care were homeless [2]. A qualitative review of 17 published papers examining the effect of homelessness on health 
status, HIV treatment adherence, and health outcomes showed that homelessness is highly prevalent among Persons living with HIV/AIDS (PLWHA) and strongly associated with poorer health status, lower adherence to antiretroviral therapy, and worse CD4 cell count and viral load outcomes [3].

\section{Homelessness in Nashville, Tennessee}

During the past 5 years, in Nashville, Tennessee, the trend of homelessness paralleled the economic growth curve that propelled a booming housing market and aggressive gentrification. In addition, the trauma, poverty, and stigmatization will exasperate the homelessness epidemic in the US and access to appropriate healthcare. Nashville officials located approximately 2300 people experiencing homelessness on an overnight count in 2017. However, local advocates estimate the number of people in Nashville living on the streets, in cars, camps, motels or in shelters at 20,000 [4].

The purpose of this study was to evaluate the effect of people experiencing homelessness on viral suppression in persons with HIV/AIDS or PLWHA in an underserved area of Middle Tennessee in 2014-2019. We hypothesize that people experiencing homelessness will have worse virologic outcomes compared to those individuals living in stable housing.

\section{Methods}

\section{Study setting}

Meharry Medical College is located at the epicenter of the HIV epidemic in North Nashville, Davidson County, in Middle Tennessee. Thirteen counties including Davidson make the Nashville Transitional Grant Area (TGA) of the Ryan White Part A program. While about 39\% of the TGA's population lives in Davidson County, $76.5 \%$ of the PLWH population resides in Davidson County. Twenty percent of them had been in jail, $42 \%$ homeless/unstably housed at some point in the last year, while $40.2 \%$ did not have food to eat three or more days at some point in the last year, according to Nashville Metro Health Department statistics. As a Tennessee-designated AIDS Center of Excellence, Meharry Community Wellness Center (MCWC) has been a major provider of comprehensive, integrated, and patient-centered care and health services for the most underserved PLWH in Davidson County since 2005.

\section{Study design}

We conducted a cross-sectional analysis of 692 HIVseropositive adult and adolescent patients seen at MCWC between 2014 and 2019. The Meharry Institutional Review Board (IRB) had approved this study.

\section{Inclusion criteria}

All adult and adolescent patients who had at least one medical visit at MCWC between January 1, 2014 and December 31, 2019 were included.

\section{Exclusion criteria}

From this study analysis, we excluded prison inmates of Tennessee Department of Corrections, seen through our telemedicine program and jail inmates who had face-to-face clinic encounters.

\section{Data sources}

Data elements extracted from CAREWare electronic patients' charts included the following: age group, race/ ethnicity, gender, HIV risk factor, federal poverty level (FPL), type of medical insurance, housing status (permanently housed and homeless), rate of clinic visits per month, last recorded CD4 cell count and plasma HIV viral load. CAREWare is an electronic health and social support services information system for HRSA's Ryan White HIV/AIDS Program recipients and providers. MCWC staff entered all data elements in CAREWare at each patient visit. We performed data quality check, for accuracy, duplication, missing, and unknown elements before generating the study database. No personal identifiers were included. Nearly all viral load and CD4 cell count results were imported from our contractual commercial lab web portal and very few of them came from external providers' reports.

\section{Measures \\ Primary outcome variable}

Viral load suppression, defined as plasma HIV viral load below the detection limit of 20 copies/mL measured by Real Time PCR assay, constituted the primary outcome variable. Of note, our viral suppression threshold is lower than commonly used 200 copies $/ \mathrm{mL}$ in published reports. The outcome variable is coded as 0 for virally suppressed and 1 for not virally suppressed.

\section{Independent variables}

We chose a pool of independent variables from patient's electronic medical records (CAREWare 6, version 58). Demographic variables consisted of age group (18-24, 25-44, 45-64, and 65+), gender (male, female and transgender), and race/ethnicity (Black or African American, non-Hispanic white, and other including Hispanic/Latinx). Variables of social determinants of health comprise HIV risk category (heterosexual, MSM, and/or bisexual men, injection drug use or IDU, and other), housing status (homeless or stable), FPL, and type of medical insurance (no insurance, Medicaid/ 
Medicare, private insurance and other). Homeless was defined as people living in shelters, transient homes, in the streets, or unable to pay rent or mortgage. We entered modified adjusted gross income (MAGI) as the percentage of FPL, computed automatically by CAREWare, and we analyzed it as a continuous variable. As a payor of last resort, the Ryan White Program provided ambulatory/outpatient medical insurance coverage to eligible, low-income, uninsured clients. We determined retention in care as the rate of monthly medical visits. The last recorded CD4 cell count and plasma viral load were collected for this study. We treated CD4 cell count and viral load as dichotomous variables $(<500$ or $\geq 500$ cells $\left./ \mathrm{mm}^{3}\right)$ and $(\leq 20$ or $>20$ copies $/ \mathrm{mL})$. We considered plasma viral load $\leq 20$ copies $/ \mathrm{mL}$ as viral suppression.

\section{Statistical analysis plan}

First, we performed exploratory data analysis and checked for data quality, distribution, and satisfaction of model assumptions. To build the model, we first entered the binary homelessness variable using a univariate binary logistic regression with its corresponding odds ratio. After that, we constructed a multivariable binary logistic regression and calculated the adjusted odds ratios with their 95\% confidence intervals to find the effect of homelessness on viral load suppression. Then, in the multivariable model we controlled for demographic, social, and clinical variables: age group, gender, race/ethnicity, type of medical insurance, FPL, HIV risk factor, rate of outpatient and HRSA visits, and CD4 cell count. Finally, we plotted a receiver operating characteristic (ROC) curve, which summarizes the tradeoff between the true positive rate (sensitivity) and false positive rate (1-specificity) for our logistic model using different probability thresholds. The area under the curve (AUC), an aggregated metric that evaluates how well our logistic regression model classifies our binary outcome variable viral load suppression at all possible cut-offs, was computed. The AUC ranges from 0.5 to 1 . The higher the AUC, the better the model is at distinguishing between patients that are virally suppressed and patients not virally suppressed. IBM SPSS version 27 was used to perform all analyses, including graphics.

\section{Results}

\section{Population characteristics}

Table 1 summarizes the main characteristics of study population. From 2014 to 2019, this study enrolled 692 HIV-seropositive patients, 498 males (72\%), 184 females (26.6\%), and 10 transgender (1.4\%). The mean follow-up period was 5.42 ( $\mathrm{SD}=4.54,95 \% \mathrm{CI}$ : $5.08-5.76)$ years and the median follow-up time was 4.32 years. The majority
Table 1 Frequency table of HIV-positive patients by housing status

\begin{tabular}{|c|c|c|c|}
\hline & Total & $\begin{array}{l}\text { Permanently } \\
\text { housed }\end{array}$ & Homeless \\
\hline Unweighted N & 692 & 500 & 192 \\
\hline \multicolumn{4}{|l|}{ Gender } \\
\hline Male & 498 & $70.8 \%$ & $75 \%$ \\
\hline Female & 184 & $27.6 \%$ & $24 \%$ \\
\hline Transgender & 10 & $1.6 \%$ & $1 \%$ \\
\hline \multicolumn{4}{|l|}{ Race/ethnicity } \\
\hline Black & 551 & $79.2 \%$ & $80.7 \%$ \\
\hline White/non-Hispanic & 104 & $14.4 \%$ & $16.7 \%$ \\
\hline Other & 37 & & \\
\hline \multicolumn{4}{|l|}{ Age group } \\
\hline 18-24 & 40 & $5.2 \%$ & $7.3 \%$ \\
\hline $25-44$ & 287 & $42 \%$ & $41 \%$ \\
\hline $45-64$ & 322 & $45 \%$ & $50.5 \%$ \\
\hline $65+$ & 43 & $7.8 \%$ & $2.1 \%$ \\
\hline \multicolumn{4}{|l|}{ HIV risk factor } \\
\hline Heterosexual & 318 & $45.4 \%$ & $47.4 \%$ \\
\hline IDU & 65 & $8.8 \%$ & $10.9 \%$ \\
\hline MSM & 296 & $44.6 \%$ & $38 \%$ \\
\hline Other & 13 & $1.2 \%$ & $3.6 \%$ \\
\hline \multicolumn{4}{|l|}{ Insurance type } \\
\hline Medicaid & 160 & $22 \%$ & $26 \%$ \\
\hline Medicare & 93 & $15 \%$ & $9.4 \%$ \\
\hline Ryan White & 260 & $32 \%$ & $52.1 \%$ \\
\hline Corrections & 14 & $3.1 \%$ & \\
\hline Private & 165 & $28.4 \%$ & $12 \%$ \\
\hline \multicolumn{4}{|l|}{ CD4 cell count } \\
\hline$<500$ & 315 & $42.6 \%$ & $53.1 \%$ \\
\hline$\geq 500$ & 377 & $57.4 \%$ & $46.9 \%$ \\
\hline \multicolumn{4}{|l|}{ HIV viral load } \\
\hline Suppressed & 477 & $78 \%$ & $22 \%$ \\
\hline Not Suppressed & 215 & $25.6 \%$ & $45.3 \%$ \\
\hline
\end{tabular}

of the patients (79.6\%) were Black/African American, $15 \%$ were non-Hispanic White, and $5.3 \%$ belonged to another race category, almost all of them identified as Hispanic/Latinx. Youth (age 18-24 years) accounted for $5.8 \%$, while the age groups $25-44,45-64$, and $65+$ years represented $41.5 \%, 46.5 \%$, and $6.2 \%$ of the study population respectively. Most of the patients $(69.1 \%$ in 2014 and $60.5 \%$ in 2019 ) lived below $100 \%$ of the Federal Poverty Level (FPL). In relation to HIV risk factor, $46 \%$ of the patients reported as heterosexual in 2019, a sharp decrease from $62.4 \%$ in 2014 . The proportion of patients identifying themselves as MSM increased from $34.8 \%$ in 2014 to $42.8 \%$ in 2019 . This reflects the current epidemic trend in the South. The proportion of patients who 
considered IDU as their HIV risk category decreased from $11.4 \%$ in 2014 to $9.4 \%$ in 2019 , reflecting the epidemic shift in opioid addiction, from inner cities to suburban and rural areas, and from Black/African American to White/Caucasian communities. This observation correlates with the overall decrease in the number of clients tested with chronic hepatitis C infection from $74 \%$ in 2014 to $57 \%$ in 2019.

\section{Main/primary clinical outcomes}

Testing for the essential biologic markers of antiretroviral treatment revealed that $54.5 \%$ of the patients had a robust CD4 cell count $\geq 500$ cells $/ \mathrm{mm}^{3}$ (HIV infection, stage 1) and $68.9 \%$ of them achieved plasma viral load suppression below the detection limit of 20 copies/mL. Permanently housed patients had a much higher proportion of viral suppression compared with their homeless counterparts. As shown in Table 2, the odds of those not virally suppressed for persons living in a stable house compared to persons in an unstable house is 0.42 with a $95 \%$ confidence interval estimate of $(0.29,0.59)$ and the adjusted odds ratio is 0.48 with a $95 \%$ confidence interval estimate of $(0.32,0.72)$. Among patients with viral load less than 20 copies $/ \mathrm{mL}, 78 \%$ were permanently/stably housed and $22 \%$ were homeless, while $74 \%$ of permanently/housed patients reached

Table 2 Odds ratios and adjusted odds ratios with their corresponding 95\% confidence intervals for binary viral load outcome

\begin{tabular}{|c|c|c|c|c|}
\hline Variable name & $\begin{array}{l}\text { Odds ratio and } 95 \% \mathrm{Cl} \text { for } \\
\text { odds ratio }\end{array}$ & P-value & $\begin{array}{l}\text { Adjusted odds ratio and } 95 \% \mathrm{Cl} \text { for } \\
\text { adjusted odds ratio }\end{array}$ & P-Value \\
\hline \multicolumn{5}{|l|}{ Housing status } \\
\hline Unstable housing & 1 & & 1 & \\
\hline Stable housing & $0.42(0.29,0.59)$ & $<0.001$ & $0.48(0.32,0.72)$ & $<0.001$ \\
\hline \multicolumn{5}{|l|}{ Gender } \\
\hline Transgender & 1 & & 1 & \\
\hline Female & $0.78(0.19,3.13)$ & 0.724 & $0.68(0.13,3.66)$ & 0.651 \\
\hline Male & $1.17(0.30,4.57)$ & 0.825 & $1.00(0.20,4.98)$ & 1.000 \\
\hline \multicolumn{5}{|l|}{ Race/Ethnicity } \\
\hline Other & 1 & & 1 & \\
\hline Black or African American & $1.26(0.60,2.65)$ & 0.549 & $1.52(0.65,3.56)$ & 0.334 \\
\hline White (non-Hispanic) & $1.10(0.47,2.54)$ & 0.833 & $1.39(0.54,3.60)$ & 0.498 \\
\hline \multicolumn{5}{|l|}{ Age group } \\
\hline 65 years old or older & 1 & & 1 & \\
\hline 18-24-year-old & $0.98(0.37,2.57)$ & 0.967 & $0.83(0.26,2.70)$ & 0.760 \\
\hline 25-44-year-old & $1.54(0.76,3.12)$ & 0.235 & $1.70(0.70,4.17)$ & 0.244 \\
\hline 45-64-year-old & $0.93(0.46,1.89)$ & 0.833 & $0.77(0.34,1.76)$ & 0.534 \\
\hline \multicolumn{5}{|l|}{ HIV risk factor } \\
\hline Other & 1 & & 1 & \\
\hline Heterosexual & $1.44(0.39,5.35)$ & 0.585 & $2.63(0.58,11.98)$ & 0.212 \\
\hline IDU & $1.48(0.37,5.97)$ & 0.580 & $2.43(0.49,12.07)$ & 0.277 \\
\hline MSM & $1.60(0.43,5.95)$ & 0.483 & $2.35(0.53,10.50)$ & 0.264 \\
\hline \multicolumn{5}{|l|}{ Insurance type } \\
\hline Private & 1 & & 1 & \\
\hline Medicaid & $1.67(1.02,2.73)$ & 0.043 & $1.16(0.62,2.18)$ & 0.638 \\
\hline Medicare & $1.07(0.59,1.96)$ & 0.821 & $0.83(0.40,1.74)$ & 0.623 \\
\hline No insurance & $2.13(1.37,3.31)$ & $<0.001$ & $1.21(0.70,2.09)$ & 0.486 \\
\hline Corrections & $1.92(0.61,6.09)$ & 0.267 & $0.90(0.24,3.41)$ & 0.881 \\
\hline \multicolumn{5}{|l|}{ CD4 cell count } \\
\hline$C D 4 \geq 500$ & 1 & & 1 & \\
\hline$C D 4<500$ & $4.65(3.28,6.59)$ & $<0.001$ & $4.93(3.38,7.21)$ & $<0.001$ \\
\hline Poverty level & $1.00(1.00,1.00)$ & $<0.001$ & $1.00(1.00,1.00)$ & 0.031 \\
\hline Rate of HRSA visits & $1.01(1.00,1.01)$ & $<0.001$ & $1.19(0.99,1.42)$ & 0.059 \\
\hline Rate of outpatient visits & $1.01(1.00,1.01)$ & $<0.001$ & $0.84(0.70,1.01)$ & 0.066 \\
\hline
\end{tabular}


viral suppression and a much smaller proportion of the homeless patients (54.7\%) remained virally suppressed.

The multivariable binary logistic regression demonstrated that permanent/stable housing ( $\mathrm{p}$-value $<0.001$ ) was a significant factor of plasma HIV viral load suppression. It also revealed that higher frequency of CD4 cell count $\geq 500$ cells $/ \mathrm{mm}^{3}$ (HIV infection, stage 1 ) (p-value $<0.001$ ) were also significant factors of viral load suppression. The remaining logistic model variables were the following: age ( $\mathrm{p}$-value $=0.004), \mathrm{FPL}$ $(\mathrm{p}$-value $=0.031)$, gender $(\mathrm{p}$-value $=0.328)$, race/ethnicity $(\mathrm{p}$-value $=0.605)$, HIV risk factor $(\mathrm{p}$-value $=0.659)$, and type of medical insurance $(\mathrm{p}$-value $=0.791)$. We found no significant interactions between housing status and other explanatory variables used in the multivariable binary logistic model. The FPL had a mean of 100.9 and standard deviation of 129.5 , while $60.5 \%$ of the clients had an annual income under $100 \%$ of FPL. As expected, patients living in permanent/stable housing had twice the chance of achieving viral suppression compared with those who were homeless [OR 0.48 (0.32-0.72), p-value $<0.001]$. The CD4 count cut-off of 500 cells $/ \mathrm{mm}^{3}$ was indeed representative of our patient population since $88.2 \%$ of them had CD4 count greater than 200 cells $/ \mathrm{mm}^{3}$. Under the nonparametric assumption, the receiver operating characteristic (ROC) curve plotted in Fig. 1 correctly predicted $72.3 \%$ of the primary outcome variable, plasma HIV viral load suppression $(\mathrm{AUC}=0.767 ; \mathrm{p}$-value $<0.001 ; 95 \% \mathrm{CI}$ for

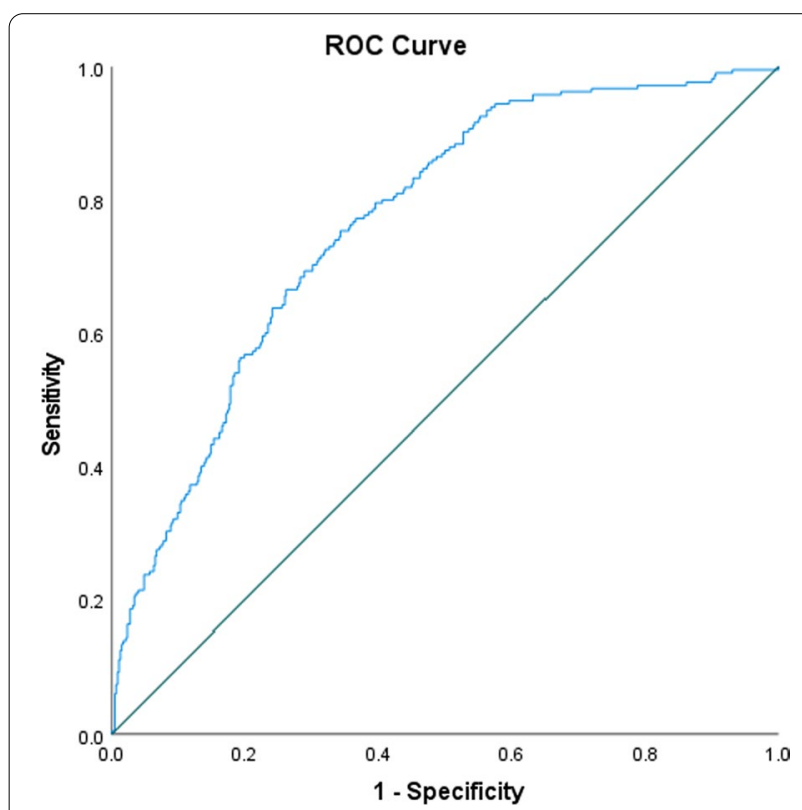

Fig. 1 Receiving Operating Characteristic (ROC) Curve
AUC $(0.73,0.80)$. The model is adequate in classifying patients who are virally suppressed and not suppressed.

During the five-year study period, 52 patients died. Of them, $16(30.76 \%)$ were homeless and $36(69.23 \%)$ lived in stable housing, while $12.5 \%$ of people experiencing homelessness and $61.12 \%$ of those in stable housing achieved viral suppression at the time of death.

\section{Discussion}

Our findings indicate that homelessness, lower retention in care and CD4 cell count less than 500 cells $/ \mathrm{mm}^{3}$ may be associated with sub-optimal viral suppression. Investigators in San Francisco drew similar conclusions from a surveillance study of $862 \mathrm{HIV}$-positive residents, showing that homelessness was independently associated with virologic failure (plasma viral load $>200$ copies $/ \mathrm{mL}$ ) [5]. A study of 95 homeless PLWHA found an odds ratio of incomplete viral suppression (plasma viral load $>75$ copies $/ \mathrm{mm}^{3}$ ) 3.84 times higher in people experiencing homelessness compared with housed persons (95\% CI 1.36-10.36) [6]. Canadian researchers investigated $922 \mathrm{HIV}$-seropositive injection drug users and found that longer duration of homelessness was associated with lower odds of viral suppression (adjusted odds ratio $=0.71$ per six-month period of homelessness, $95 \%$ CI 0.60-0.83) [7]. Researchers in San Francisco discovered a relationship between greater housing instability and lower rates of virologic suppression, ranging from $42 \%$ (living outdoors) to $85 \%$ (rent/own dwelling) among 1,222 HIV patients [8]. The CDC HIV/AIDS Surveillance Project, including 304 homeless across 19 sites throughout the United States demonstrated that PLWHA experiencing homelessness had lower adherence to antiretroviral treatment, lower CD4 cell count, lower likelihood of viral suppression [9]. Another multisite study among 3082 participants in New York, Chicago, Washington, DC, and Los Angeles showed that unstable housing reduced the probability of viral suppression and adequate CD4 cell count by $51 \%$ and $53 \%$ respectively [10]. Supportive housing program such as Shelter Plus Care, in Cincinnati, Ohio, had achieved statistically significant improvements on CD4 cell count (> 500 cells/ $\mathrm{mm}^{3}$ ) and viral suppression (plasma viral load $<200$ copies $/ \mathrm{mL}$ ), $45 \%$ and $79 \%$ respectively [11].

Many studies have shown that incarceration is associated with poor health outcomes among HIV-seropositive adults including greater use of emergency room visits and hospital admissions, and lower prevalence of viral suppression [12, 13]. According to the Brookings Institution, North Nashville has an incarceration rate of $14 \%$, the highest in the country by far, and $93 \%$ of those incarcerated are Blacks. In other words, one in seven people who were born in the primary zip code of North 
Nashville between 1980 and 1986 went to jail or prison at some point in their lives [14]. Twenty five percent of our patients reside in that neighborhood and $41 \%$ of them belong to this age group.

Strengths of our study include use of a population disproportionately affected by homelessness and HIV/AIDS, adequate sample size and follow-up duration, and collection of data using validated measures. Nonetheless, this cross-sectional study has several limitations. First, our study has weaknesses inherent to cross-sectional analysis, but we find it reassuring that our results arrive at the consistent message that homelessness contributes to suboptimal viral suppression in PLWHA. It does not clearly establish homelessness as an independent factor of virologic failure because the study did not address other wellknown predictive variables (mental health, substance use disorders, health literacy/numeracy, etc.) in the multivariable binary logistic regression. Nonetheless, a theoretical mathematical model analyzing the effect of homelessness on HIV/AIDS transmission dynamics and comparing housing status-induced reproduction numbers suggests that lack of entertainment, poor nutrition, and co-infection with other sexually transmitted infections in individuals experiencing homelessness may enhance HIV transmission and AIDS-related deaths [15]. The Research on Access to Care in the Homeless (REACH) recruited 104 participants from San Francisco homeless shelters, free-meal programs, and single room-occupancy hotels charging less than $\$ 600 /$ month. They discovered that severely food unsecure participants had $>80 \%$ lower likelihood of adherence and 77\% lower odds of viral suppression (viral load < 50 copies/mL) (95\% CI: 0.06-0.82) [16]. A prospective cohort study of $288 \mathrm{HIV}$-seropositive people experiencing homelessness and unstably housed men, conducted in San Francisco between 2002 and 2008 concluded that the inability to meet food, hygiene, and housing needs was the most powerful factor of physical and mental health, after adjusting for age, race, income, and CD4 cell count [17]. These factors are important because $30 \%$ of our patients are facing challenging mental health issues and substance use disorders. More than $50 \%$ of our patients did not graduate from high school. The majority of them read at fifth grade level and lack the emotional and familial support to deal with their illnesses in a community with pervasive stigma.

Second, our study does not reflect the racial/ethnic representation of the general population. For example, the proportion of Hispanic/Latinx and transgender communities is relatively small. However, HIV/AIDS and homelessness affect primarily underserved Black/African American communities. Nevertheless, other studies have shown that housing status could be a major factor of HIV health outcomes than demographic features, mental health, substance use disorders, or utilization of other services.

Third, the study does not account for non-infectious comorbidities that could have contributed to higher rates of hospitalizations and emergency room visits, more frequent drug interactions, intolerance, and side effects, leading to sub-optimal treatment adherence and lower rate of viral load suppression, and higher mortality. These critical issues deserve utmost attention because HIV infection may contribute to chronic, sub-clinical inflammation, which promotes the development of cardiovascular and metabolic complications. Notwithstanding the study limitations, multiple researchers have reported the findings that homelessness may be associated with suboptimal viral suppression.

\section{Conclusions}

Stigmatization and marginalization of individuals experiencing homelessness and HIV-seropositive persons, implicit bias and discrimination, antiquated housing laws, and unfair criminal justice system deserve renewed attention of federal, state, and local authorities. As a public health intervention, housing services align with national medical priorities such as disease prevention and unfettered access to cost-effective and quality health care. At the core of the conceptual framework of the syndemic affecting Black/African Americans in Nashville, Tennessee, HIV/AIDS, homelessness, incarceration, socio-economic status, substance use disorder are intertwined and should be addressed collectively.

\section{Abbreviations}

ACA: Affordable Care Act; ACCESS: AIDS care cohort to evaluate exposure to survival services; AIDS: Acquired immunodeficiency syndrome; aRH: Adjusted relative hazard; ART: Antiretroviral treatment; AUC: Area under the curve; CD4: CD4 T lymphocytes; CDC: Centers for disease control and prevention; $\mathrm{Cl}$ : Confidence interval; FPL: Federal poverty level; HIV: Human immunodeficiency virus; HOPWA: Housing opportunities for people with AIDS; HPTN 052: HIV prevention trials network; IAP: Insurance assistance program; IDU: Injection drug use; iPrEx: Preexposure prophylaxis initiative; IRB: Institutional review board; MAGI: Modified adjusted gross income; MCWC: Meharry Community Wellness Center; MSM: Men having sex with men; OR: Odds ratio; PARTNER: Partners of People on ART_-A New Evaluation of the Risks; PCR: Polymerase chain reaction; PEP: Post-exposure HIV prophylaxis; PLWHA: Persons living with HIV/AIDS; PLWH: People living with HIV; PrEP: Pre-exposure HIV prophylaxis; REACH: Research on Access to Care in the Homeless; ROC: Receiver operating characteristic; SARS: Severe acute respiratory syndrome; SARS-COV-2: Severe acute respiratory syndrome coronavirus 2; TGA: Nashville transitional grant area; WIHS: Women's Interagency HIV Study.

\section{Acknowledgements}

We acknowledge the invaluable contribution of Takizala, Zudi-Mwak, MBA $M D, M P H$, for working diligently on the regulatory procedures and submission to the Meharry Medical College Institutional Review Board.

\section{Authors' contributions}

VB was the overall leader of this project. MT and DW performed data mining and data curation as well as all statistical analysis in this paper. VB, MT, and DW wrote the manuscript. MB collected the data. $L J, R J, M C, A O, P J$, and PMJ read 
and edited the manuscript for scientific content. All authors have read and approved the final manuscript.

\section{Funding}

Dr. Berthaud received primary Grant support from Human Resources and Services Administration/HIV/AIDS Bureau, Grants U90HA29237, HL6HA01706 and H7CHA36789. Tennessee Health Department AIDS Centers of Excellence and Ryan White Part B Grants 34349-90218 and 34349-87418 funded part of this project. Metropolitan Nashville Health Department Ryan White Part A also supported this project under Grants 357545, 357504, 357557, 357539, and 357555. The National Institute of Health/National Institute of Allergy and Infectious Diseases, Tennessee Center for AIDS Research Grant P30 Al1 10527 supported part of this research. Dr. Berthaud also received Grant funding from the Department of Housing and Urban Development/Metropolitan Department of Housing Authority and United Way of Middle Tennessee in direct funding for this project. The funders had no role in study design, data collection and analysis, decision to publish, or preparation of the manuscript. The Meharry Medical College RCMI Grant (NIH Grant MD007586) supported the following authors: Dr. Tabatabai and Mr. Wilus. HRSA has partially funded this project under Grant number UH1HP30348 for Dr. Tabatabai. This information or content and conclusions are those of the authors. The reader should not construct them as the official position or policy of, nor infer any endorsements by RCMI or HRSA.

\section{Availability of data and materials}

The datasets generated and/or analyzed during the current study are not publicly available due to the personal nature of the data and are not available from the corresponding author upon request.

\section{Declarations}

\section{Ethics approval and consent to participate}

The Meharry Medical College Institutional Review Board (IRB) had reviewed and approved this study. This research involved the collection or study of existing data that was already recorded by the investigator in such a manner that subjects cannot be identified, directly or through identifiers linked to the subjects. Individual consent was not applicable.

\section{Consent to publication}

Not applicable.

\section{Competing interests}

The authors declare that they have no competing interests.

\section{Author details}

${ }^{1}$ Division of Infectious Diseases, Meharry Community Wellness Center, Meharry Medical College, Nashville, TN, USA. ${ }^{2}$ School of Graduate Studies and Research, Meharry Medical College, Nashville, TN, USA. ${ }^{3}$ Department of Family and Community Medicine, Meharry Medical College, Nashville, TN, USA.

Received: 4 November 2020 Accepted: 29 January 2022

Published online: 10 February 2022

\section{References}

1. Centers for Disease Control and Prevention. Estimated HIV incidence and prevalence in the United States, 2014-2018. HIV Surveillance Report, Supplemental Report, volume 24, Number 1.

2. CDC HIV Prevention Progress Report, 2019. Downloaded on 12 May 2020 at: https://www.cdc.gov/hiv/pdf/policies/progressreports/cdc-hiv-preve ntionprogressreport.pdf.

3. Milloy M-J, Marshall BDL, Montaner J, Wood E. Housing status and the health of people living with HIV/AIDS. Curr HIV/AIDS Rep. 2012;9(4):364-74.

4. Craig T. Homeless deaths surge. The Washington Post, 2018.

5. Muthulingam D, Chin J, Hsu L, et al. Disparities in engagement in care and viral suppression among persons with HIV. J Acquir Immune Defic Syndr. 2013;63:112-9.
6. Thakarar K, Morgan JR, Gaeta JM, et al. Homelessness, HIV, and incomplete viral suppression. J Health Care Poor Underserved. 2016;27(1):145-56.

7. Loh J, Kennedy MC, Wood E, et al. Longer duration of homelessness is associated with a lower likelihood of non-detectable plasma HIV-1 RNA viral load among people who use illicit drugs in a Canadian setting. AIDS Care. 2016;28(11):1448-54.

8. Clemenzi-Allen A, Geng E, Christopoulos K, et al. Degree of housing instability shows independent "dose-response" with virologic suppression rates among people living with human immunodeficiency virus. Open Forum Infect Dis. 2018;5:1-3.

9. Kidder DP, Wolitski RJ, Campsmith ML, et al. Health status, health care use, medication use, and medication adherence among homeless and housed people living with HIV/AIDS. Am J Public Health. 2007;97(12):2238-45.

10. Health Resources and Services Administration. Ryan White HIV/AIDS Program Annual Client-Level Data Report 2018. http://hab.hrsa.gov/data/ data-reports. Published December 2019. Accessed May 1, 2020.

11. Bowen EA, Canfield J, Moore S, et al. Predictors of CD4 health and viral suppression outcomes for formerly homeless people living with HIV/AIDS in scattered site supportive housing. AIDS Care. 2017;29(11):1458-62.

12. Nasrullah M, Frazier EL, Fagan J, et al. The association of recent incarceration and health outcomes among HIV-infected adults receiving care in the United States. Int J Prison Health. 2016;12(3):135-44.

13. Lim S, Nash D, Hollod L, et al. Influence of jail incarceration and homelessness patterns on engagement in HIV care and HIV viral suppression among New York City adults living with HIV/AIDS. PLoS ONE. 2015;10:1-12.

14. Adams L, Nicholas T. Work and opportunity before and after incarceration. The Brookings Institution, 2018.

15. Bhunu CP. Assessing the impact of homelessness on HIV/AIDS transmission dynamics. Cogent Math. 2015;2:2-13.

16. Weiser SD, Frongillo EA, Ragland K, et al. Food insecurity is associated with incomplete HIV RNA suppression among homeless and marginally housed HIV-infected individuals in San Francisco. I Gen Intern Med. 2008;24:14-20

17. Riley ED, Neilands TB, Moore K, et al. Social, structural and behavioral determinants of overall health status in a cohort of homeless and unstably housed HIV-infected men. PLoS ONE. 2012;7(4):1-7.

\section{Publisher's Note}

Springer Nature remains neutral with regard to jurisdictional claims in published maps and institutional affiliations.
Ready to submit your research? Choose BMC and benefit from:

- fast, convenient online submission

- thorough peer review by experienced researchers in your field

- rapid publication on acceptance

- support for research data, including large and complex data types

- gold Open Access which fosters wider collaboration and increased citations

- maximum visibility for your research: over 100M website views per year

At BMC, research is always in progress.

Learn more biomedcentral.com/submissions 